\title{
Sazonalidade e rotas de coleta influenciam a ocorrência de leite instável não ácido, a densidade e a crioscopia do leite fornecido a um laticínio no Norte de Minas Gerais
}

\author{
[Seasonality and collection routes influence the occurrence of non-acid \\ unstable milk, the density and cryoscopy of milk supplied to a dairy \\ industry in northern Minas Gerais]
}

\section{L.R. Oliveira ${ }^{1}$, A.D. Mathias $^{2}$, M.S. Pinto ${ }^{3}$, R.R. Wenceslau ${ }^{4}$, N.J.F. Oliveira ${ }^{3 *}$}

${ }^{1}$ Aluna de pós-graduação - Universidade Federal de Uberlândia, Uberlândia, MG

${ }^{2}$ Aluno de pós-graduação - Instituto de Ciências Agrárias - Universidade Federal de Minas Gerais - Montes Claros, MG

${ }^{3}$ Instituto de Ciências Agrárias - Universidade Federal de Minas Gerais - Montes Claros, MG

${ }^{4}$ Escola de Veterinária - Universidade Federal de Minas Gerais - Belo Horizonte, MG

\section{RESUMO}

Objetivou-se avaliar, nos meses, nas estações do ano e nas rotas de coleta, a ocorrência de leite instável não ácido (LINA) e de outras classes de leite, de acidez titulável, densidade e crioscopia em 10.654 resultados de laticínio localizado em Montes Claros, MG. Em rotas de coleta, agruparam-se:a)Bocaiúva; Brasília de Minas, Coração de Jesus e São João da Lagoa; b) Capitão Enéas e Janaúba; Francisco Sá; c) Icaraí de Minas e São Francisco; d)Juramento e Glaucilândia; e) Montes Claros; f) Pedras de Maria da Cruz, Japonvar, Lontra e São João da Ponte; g) Ubaí. Foram avaliados frequências das classes de leite, teste do álcool, acidez titulável, densidade e crioscopiapor mês, estação do ano e rota. Com testes de qui-quadrado e análises de variância, verificou-se influência de mês, estação do ano e rota em acidez titulável, densidade e crioscopia. Análises de correspondência múltipla descreveram a associação de classes de leite e mês ou rotas e de teste do álcool, acidez titulável, densidade e crioscopia em relação às estações do ano.Por regressão logística, calculou-se probabilidade de ocorrência de LINA por grupos de meses e de rotas. Houve maior porcentagem de amostras dentro da normalidade. Resultados normais, LINA, amostras alcalinas e ácidas foram, respectivamente, 79,46\%; 12,93\%; 4,14\% e 3,48\% de 10.271 resultados. Positividade ao teste do álcool $(\mathrm{n}=10.561)$ foi mais frequente no final do inverno. LINA associou-se à transição da seca para chuva, com maior chance de ocorrência em setembro e janeiro. As rotas de Brasília de Minas, Icaraí de Minas e Ubaí apresentaram maiores desconformidades e probabilidades para ocorrência de LINA.

Palavras-chave: estabilidade ao álcool, alizarol, coagulação, estabilidade do leite

\begin{abstract}
The purpose of this study was to evaluate in the months, seasons and collection routes, the occurrence of nonacidic unstable milk (UNAM) and other milk categories, titratable acidity, density and cryoscopy in 10,654 samples from a dairy industry located in Montes Claros, MG, Brazil. Municipalities were grouped in collection routes: a) Bocaiúva; Brasília de Minas, Coração de Jesus and São João da Lagoa; b) Capitão Enéas and Janaúba; c) Francisco Sá; Icaraí de Minas and São Francisco; d) Juramento and Glaucilândia; e) Montes Claros; f) Pedras de Maria da Cruz, Japonvar, Lontra and São João da Ponte and g) Ubaí. The milk category frequencies and alcohol test, titratable acidity, density and cryoscopy of milk by months, season and routes were evaluated. Chi-square tests and variance analysis showed the influence of month, season and route on titratable acidity, density and cryoscopy. Multiple correspondence analyzes described the association of milk and month or routes and alcohol test categories, titratable acidity, density and cryoscopy in relation to the seasons. The probability of occurrence of LINA by month and route groups was calculated by logistic regression. There were a higher percentage of samples within the normal range. Normal, UNAM, alkaline and acid milk results were respectively $79.46,12.93,4.14$ and $3.48 \%$ of 10,271 results. Alcohol test positivity $(n=10,561)$ was more frequent
\end{abstract}

Recebido em 13 de fevereiro de 2019

Aceito em 6 de janeiro de 2020

*Autor para correspondência (corresponding author)

E-mail: neideufmg@gmail.com 
in late winter. UNAM was associated with the transition from drought to rainy season, most likely to occur in September and January. The Brasília de Minas, Icaraí de Minas and Ubaí routes presented higher nonconformities and probabilities for UNAM occurrence.

Keywords: ethanol stability, alizarol, coagulation, milk stability

\section{INTRODUÇÃO}

No norte de Minas Gerais, foram produzidos aproximadamente 221.511 mil litros de leite em 2017, correspondentes a 2,5\% do total ordenhado no mais produtivo estado do Brasil. Na região, encontram-se 3,8\% dos laticínios do estado, e as médias são $4,1 \mathrm{~L}$ por animal ao dia e $1.249,7 \mathrm{~L}$ por vaca no ano produtivo (305 dias), segundo a Secretaria de Estado de Agricultura, Pecuária e Abastecimento de Minas Gerais (Bovinocultura..., 2019).

A legislação nacional relacionada aos padrões de qualidade do leite é regida por Instruções Normativas $N^{\circ} 76$ (Brasil, 2018a) e N77 (Brasil, 2018b). Estas entraram em vigor em 2018, substituindo a Portaria Dilei/Sipa/SNAD/MA N ${ }^{\circ}$ 08, de 26 de junho de 1984; a Instrução Normativa $\mathrm{N}^{\circ}$ 51, de 18 de setembro de 2002; a Instrução Normativa SDA/Mapa $\mathrm{N}^{\mathrm{o}} 22$, de 07 de julho de 2009; a Instrução Normativa $\mathrm{N}^{\circ} 62$, de29 de dezembro de 2011; a Instrução Normativa $N^{\circ} 07$, de 03 de maio de 2016; e a Instrução Normativa $\mathrm{N}^{\mathrm{o}} 31$, de 29 de junho de 2018.

Quando comparadas as legislações, os limites de acidez titulável, de 14 a $18^{\circ} \mathrm{D}$ e de densidade, de 1.028 a $1.034 \mathrm{~g} . \mathrm{mL}^{-1}$, continuaram os mesmos. Entretanto, para crioscopia, atualmente são aceitos $-0,512$ a $-0,536^{\circ} \mathrm{C}$ versus $-0,512$ a $-0,531$, descritos na Instrução Normativa $N^{\circ} 62$ (Brasil, 2011).A ocorrência de leite instável não ácido (LINA) causa prejuízos aos produtores e laticínios, em consequência da penalização aos primeiros e do risco de coagulação da matériaprima em alguns processamentos térmicos na indústria (Fagnani et al., 2018).Para ser LINA, a matéria-prima é instável ao teste do álcool a $72 \%$ (v/v), sem apresentar acidez titulável acima de $18^{\circ} \mathrm{D}$ (Gabbi et al., 2016).

Estudos sobre LINA em regiões tropicais semiáridas são raros (Faria et al., 2017). Fernandes et al. (2013) descreveram essas regiões como predisponentes à perda da estabilidade do leite, a condições climáticas quentes e secas, além da predominância de ordenha de vacas mestiças e criadas em sistemas extensivos de produção, situações comuns no norte de Minas Gerais.
É importante conhecer a dinâmica da ocorrência de LINA em diferentes locais e estações do ano (Li et al., 2019), pois essa alteração é de origem complexa e multifatorial, segundo Fagnani et al. (2018). Portanto, objetivou-se estudar, nos meses, nas estações do ano e nas rotas de coleta, a ocorrência de LINA e de outras classes de leite, de acidez titulável, densidade e crioscopia, em um laticínio localizado no norte de Minas Gerais.

\section{MATERIAL E METÓDOS}

Utilizaram-se resultados do banco de dados de um laticínio localizado no município de Montes Claros, Minas Gerais, Brasil. A coleta de amostras de leite abrangeu janeiro a dezembro de 2014, sendo o total de 10.654 amostras, provenientes de 290 unidades produtoras de leite (UPL), distribuídas em 18 cidades da região do norte de Minas Gerais. Os municípios amostrados foram: Bocaiúva, Brasília de Minas, Capitão Enéas, Coração de Jesus, Francisco Sá, Glaucilândia, Icaraí de Minas, Janaúba, Japonvar, Juramento, Lontra, Mirabela, Montes Claros, Pedras de Maria da Cruz, São Francisco, São João da Lagoa, São João da Ponte e Ubaí. As UPL eram pequenas e médias, a maioria sendo explorada com padrão de produção familiar e com baixa tecnificação.

Em 2014, nas propriedades rurais, o leite foi coletado por técnicos treinados, sendo retirado diretamente de tanques a granel individuais ou coletivos de até 4.000 litros, com intervalo de armazenamento de $48 \mathrm{~h}$ após a ordenha e temperatura do conteúdo menor ou igual a $4^{\circ} \mathrm{C}$. Cada amostra correspondia a $300 \mathrm{~mL}$ de leite de cada tanque, obtido com auxílio de concha de aço inoxidável após homogeneização por cinco ou $10 \mathrm{~min}$, para tanques de até $3.000 \mathrm{~L}$ ou superiores a $3.000 \mathrm{~L}$, respectivamente, conforme Brasil (2011), legislação vigente na época da coleta. Os recipientes para coleta eram frascos de polipropileno higienizados com detergentes industriais, enxaguados em água clorada, desinfetados com hipoclorito de sódio e secos em estufa a $40^{\circ} \mathrm{C}$, não tendo sido adicionados conservantes.

Nas UPL, o leite foi submetido ao teste do álcool a $80 \%(\mathrm{v} / \mathrm{v})$ para se verificar a estabilidade 
térmica. Independentemente de os resultados serem positivos ou negativos, as amostras foram identificadas, colocadas em caixas isotérmicas contendo gelo reciclável e transportadas até o laticínio na cabine do caminhão. Por se tratar de linha industrial de recebimento do leite, não foram realizadas replicatas das análises,e cada amostra de leite proveniente de um tanque a granel constituiu uma repetição. O tempo de transporte das amostras na caixa isotérmica variou entre três e12 horas. $\mathrm{Na}$ chegada ao laticínio, foram admitidas para análise somente amostras com temperatura igual ou inferior a $10^{\circ} \mathrm{C}$. As análises foram realizadas por técnicos de laboratório da empresa, obedecendo-se aos parâmetros estabelecidos na legislação (Brasil, 2011), vigente na época da coleta.

Conforme a proximidade entre as UPL, as distâncias entre os pontos de coleta e as linhas de captação de leite, os 18 municípios foram agrupados em nove rotas. Estas e os respectivos números de amostras foram: a)Bocaiúva, $\mathrm{n}=461$; b)Brasília de Minas, $n=1.227$, correspondente aos municípios de Brasília de Minas, Coração de Jesus e São João da Lagoa; c) Capitão Enéas, n=1.299, associado a Janaúba; Francisco Sá, $\mathrm{n}=2.793$; d)Icaraí de Minas, $\mathrm{n}=595$, juntamente com São Francisco; e) Juramento, $n=757$, com Glaucilândia; f) Montes Claros, n=1.997; Pedras de Maria da Cruz, n=438, agrupada a Japonvar, Lontra e São João da Ponte; e g) Ubaí, n=1.087, totalizando 10.654 amostras.

Avaliou-se a estabilidade ao álcool nas concentrações (v/v) de 76\%, 75\%, 74\% e $72 \%$. Amostras com floculação na prova a $72 \%$ foram submetidas ao teste de acidez titulável, sendo consideradas LINA aquelas com acidez entre $14 \mathrm{e}$ 18 graus Dornic. Quatro classes de amostras de leite foram identificadas conforme acidez titulável e reação ao teste do álcool a $72 \%$, sendo: leite normal: acidez entre 14 e $18^{\circ} \mathrm{D}$, estável ao álcool; LINA: acidez entre 14 e $18^{\circ} \mathrm{D}$, instável ao álcool; leite alcalino: acidez inferior a $14^{\circ} \mathrm{D}$, estável ao álcool; leite ácido: acidez acima de $18^{\circ} \mathrm{D}$, instável ao álcool. Quanto à densidade e à crioscopia, amostras no intervalo de 1.028 a $1.034 \mathrm{~g} . \mathrm{mL}^{-1} \mathrm{e}-$ 0.512 a $-0.540^{\circ} \mathrm{C}$, respectivamente, foram consideradas normais, conforme descrito em Brasil (2018a).

Análises de consistência foram realizadas, procedendo-se à eliminação de dados discrepantes nos 10.654 resultados. Para as variáveis categóricas, obtiveram-se $n=10.271$ e $n=10.561$ amostras para classes de leite e teste do álcool, nesta ordem.Na avaliação das variáveis quantitativas, acidez titulável, densidade e crioscopia, consideraram-se, respectivamente, 9.357; 9.165 e 9.752 resultados. No estudo da influência da estação do ano nos parâmetrosteste do álcool, acidez titulável, densidade e crioscopia, a frequência de classes de leite foi avaliada em duas épocas do ano. A estação seca foi considerada de abril a outubro e a chuvosa,de novembro a março, segundo a classificação exposta por Álvares et al. (2013).

As frequências das classes de leite foram obtidas para cada mês, estação do ano e rota de coleta. Avaliou-se a ocorrência de amostras dentro ou fora dos padrões estabelecidos na Instrução Normativa $\mathrm{N}^{\circ} 76$ (Brasil, 2018a) para teste de álcool a 72\%, acidez titulável, densidadee crioscopia. Testes estatísticos de qui-quadrado $(\mathrm{P}<0,05)$ foram realizados por meio do procedimento PROC FREQ dosoftware SAS 9.4. Análises de variância (teste F) foram feitas parase verificar influência de mês, estação do ano e rota quanto à acidez titulável, densidadee crioscopia, usando o procedimento PROC GLM do SAS 9.4 (Base..., 2011).

Para descrever a associação entre classes de leite e mês ou rotas e para avaliar resultados do teste de álcool, acidez titulável, densidadee crioscopiaem relação às estações do ano, foram feitas análises de correspondência múltiplamediante o uso do procedimento PROC CORRESP do SAS 9.4. Para avaliar o efeito do mês e dos grupos de rotas nas classes estudadas, utilizaram-seanálises de variância. As médias dos grupos foram comparadas com teste $\mathrm{T}(\mathrm{P}<0,05)$ por meio do procedimento PROC GLM do SAS 9.4 (Base..., 2011).

A probabilidade de ocorrência de LINA por grupos de meses e rotas de coleta foi calculada por regressão logística, com o procedimento PROC LOGÍSTICA do SAS 9.4. O modelo para a variável binária, LINA ou não LINA, foi descrito como: $\ln \left(\frac{P_{i j k}}{1-P_{i j k}}\right)=\beta_{0}+\beta_{1} x_{1 i}+\beta_{2} x_{2 j}+$ $\varepsilon_{i j k}$, em que: $P_{i j k}$ é a probabilidade de espécime de leite $\mathrm{k}$ do grupo de rota de coletas ser amostrada no grupo de meses $\mathrm{j}$ para ser LINA; $\beta_{0}$ é a constante geral relacionada com a probabilidade média de ocorrência de LINA; $\beta_{1}$ e $\beta_{2}$ são os coeficientes de regressão relacionados aosefeitos 
de rota e mêsnaprobabilidadede LINA; $\varepsilon_{i j k} \varepsilon$ é o efeito residual aleatório associado a cada observação.

\section{RESULTADOS}

As ocorrências de amostras de leite normal, LINA, alcalino e ácido foram 79,46; 12,93; 4,14 e $3,48 \%$, respectivamente. Houve diferença na dispersão das classes de leite normal, LINA, alcalino e ácido entre os meses $\left(\chi^{2}=673,51\right.$; $\mathrm{P}<0,05)$ e estações do ano $\left(\chi^{2}=18,39 ; \mathrm{P}<0,05\right)$. Avaliando-se separadamente a variável LINA, constatou-se maior ocorrência $\left(\chi^{2}=176,67\right.$; $\mathrm{P}<0,05)$ em setembro, outubro e novembro, na transição do período seco para o chuvoso. Ocorreu similaridade estatística ao se considerar LINA e as outras classes de leite nas estações do ano. Conforme Tab. 1, a ocorrência de LINA foi superior $\left(\chi^{2}=147,48 ; \mathrm{P}<0,05\right)$ nas rotas de Ubaí $(15,94 \%)$ e de Brasília de Minas $(15,17 \%)$.

Tabela 1. Distribuição de frequência das classes de amostras de leite normal, leite instável não ácido (LINA), leite alcalino, leite ácido e de amostras não conformes, quanto aos resultados do teste do álcool, da acidez titulável, da densidade e da crioscopia, oriundas de laticínio do Norte de Minas Gerais e coletadas em diferentes rotas ao longo do ano de 2014

\begin{tabular}{|c|c|c|c|c|c|c|c|c|}
\hline \multirow[b]{2}{*}{ Meses } & \multicolumn{3}{|c|}{ Classes de leite $(\%)$} & \multicolumn{5}{|c|}{ Amostras fora do padrão (\%) } \\
\hline & Normal & LINA & Alcalino & Ácido & $\begin{array}{c}\begin{array}{c}\text { Prova } \\
\text { do } \\
\text { álcool } \\
\mathrm{n}=10561\end{array} \\
\text { a }\end{array}$ & $\begin{array}{l}\text { Acidez } \\
\text { titulável } \\
\mathrm{n}=9357\end{array}$ & $\begin{array}{l}\text { Densidade } \\
\mathrm{n}=9165\end{array}$ & $\begin{array}{c}\text { Crioscopia } \\
n=9752\end{array}$ \\
\hline Janeiro & 76,03 & 16,34 & 1,57 & 6,07 & 29,99 & 11,52 & 3,19 & 9,64 \\
\hline Fevereiro & 81,03 & 7,71 & 7,54 & 3,72 & 15,09 & 13,55 & 2,03 & 5,68 \\
\hline Março & 77,03 & 10,89 & 7,01 & 5,07 & 16,59 & 12,43 & 4,88 & 6,17 \\
\hline Abril & 83,80 & 10,35 & 2,31 & 3,53 & 14,13 & 5,86 & 4,17 & 8,32 \\
\hline Maio & 85,91 & 11,16 & 0,68 & 2,25 & 13,63 & 3,03 & 1,41 & 4,99 \\
\hline Junho & 88,71 & 8,80 & 1,13 & 1,35 & 11,60 & 2,49 & 1,14 & 3,50 \\
\hline Julho & 88,96 & 8,91 & 0,58 & 1,55 & 10,55 & 2,13 & 1,71 & 1,97 \\
\hline Agosto & 79,09 & 14,55 & 3,48 & 2,88 & 18,03 & 6,37 & 3,32 & 1,36 \\
\hline Setembro & 62,87 & 21,76 & 7,98 & 7,39 & 33,14 & 15,40 & 3,50 & 7,27 \\
\hline Outubro & 65,12 & 18,92 & 12,90 & 3,07 & 25,16 & 16,01 & 5,38 & 7,26 \\
\hline Novembro & 75,13 & 20,99 & 1,59 & 2,29 & 26,86 & 4,76 & 4,33 & 5,11 \\
\hline Dezembro & 81,66 & 13,45 & 1,77 & 3,13 & 23,92 & 7,06 & 2,85 & 4,91 \\
\hline \multicolumn{9}{|l|}{ Estação do ano } \\
\hline Seca (abril a outubro) & 80,36 & 12,87 & 3,94 & 2,83 & 17,02 & 6,81 & 2,91 & 4,80 \\
\hline $\begin{array}{l}\text { Chuvosa } \\
\text { (novembro a } \\
\text { março) }\end{array}$ & 78,31 & 13,00 & 4,39 & 4,30 & 21,89 & 10,79 & 3,44 & 6,59 \\
\hline \multicolumn{9}{|l|}{ Rotas* } \\
\hline Bocaiúva & 85,56 & 7,66 & 5,25 & 1,53 & 10,41 & 7,43 & 3,78 & 2,31 \\
\hline Brasília de Minas & 76,18 & 15,17 & 4,97 & 3,68 & 21,45 & 9,54 & 2,48 & 6,64 \\
\hline Capitão Enéas & 81,66 & 10,93 & 4,31 & 3,11 & 16,89 & 8,22 & 3,75 & 5,38 \\
\hline Francisco Sá & 80,75 & 12,79 & 4,10 & 2,37 & 18,03 & 7,11 & 3,08 & 4,96 \\
\hline Icaraí de Minas & 75,48 & 12,96 & 5,43 & 6,13 & 21,84 & 12,77 & 1,92 & 7,84 \\
\hline Juramento & 84,71 & 10,06 & 4,27 & 0,96 & 15,23 & 5,68 & 4,40 & 3,48 \\
\hline Montes Claros & 77,72 & 14,05 & 4,34 & 3,88 & 20,16 & 8,91 & 4,21 & 6,06 \\
\hline $\begin{array}{l}\text { Pedras de Maria da } \\
\text { Cruz }\end{array}$ & 82,28 & 11,89 & 2,80 & 3,03 & 16,89 & 6,54 & 1,10 & 7,67 \\
\hline Ubaí & 74,90 & 15,94 & 1,89 & 7,27 & 27,13 & 10,20 & 1,67 & 6,14 \\
\hline Total & 79,46 & 12,93 & 4,14 & 3,48 & 19,22 & 8,37 & 3,15 & 5,57 \\
\hline
\end{tabular}

Nota -*Rotas: Bocaiúva (Bocaiúva); Brasília de Minas (municípios de Brasília de Minas, Coração de Jesus e São João da Lagoa); Capitão Enéas (Capitão Enéas e Janaúba); Francisco Sá (Francisco Sá); Icaraí de Minas (Icaraí de Minas e São Francisco); Juramento (Juramento e Glaucilândia); Montes Claros (Montes Claros); Pedras de Maria da Cruz (Pedras de Maria da Cruz, Japonvar, Lontra e São João da Ponte); e Ubaí.

As amostras positivas ao teste do álcool a $72 \%$ foram $2.030(19,22 \%)$, conforme a Tab.1. A distribuição de amostras positivas ao teste do álcool diferiu $\left(\chi^{2}=337,56 ; \mathrm{P}<0,05\right)$ em julho, com
10,55\%, e em setembro, com 33,14\% (Tab.1). Observou-se maior porcentagem $\left(\chi^{2}=39,96\right.$; $\mathrm{P}<0,05)$ de alíquotas positivas, $21,89 \%$, no período chuvoso, se comparado ao seco, com 
17,02\% (Tab.1). A rota de Ubaí resultou em maior frequência $\left(\chi^{2}=89,55 ; \mathrm{P}<0,05\right)$ de amostras fora do padrão,27,13\%, seguida por Icaraí de Minas, com 21,84\%, e Brasília de Minas, com 21,45\% (Tab.1).

Ocorreu diferença na dispersão de amostras fora do padrão de acidez titulável entre os meses $\left(\chi^{2}=312,05 ; \quad \mathrm{P}<0,05\right)$ e as estações do ano $\left(\chi^{2}=45,98 ; \mathrm{P}<0,05\right)$. Maiores desconformidades ocorreram em outubro $(16,01 \%)$ e setembro $(15,40 \%)$, sendo mais elevadas na estação chuvosa. A rota Icaraí de Minas apresentou maior ocorrência de amostras fora do padrão de acidez titulável, correspondendo a 12,77\% (Tab.1).

Foi verificada diferença nas distribuições de amostras fora dos padrões de densidade $\left(\chi^{2}=55,74, \quad \mathrm{P}<0,05\right)$ e crioscopia $\left(\chi^{2}=110,72\right.$; $\mathrm{P}<0,05)$. Maior frequência de densidade não conforme ocorreu em outubro $(5,38 \%)$ e março $(4,88 \%)$, enquanto para crioscopia, em janeiro $(9,64 \%)$ e abril $(8,32 \%)$ (Tab.1). Em relação às estações do ano, houve efeito significativo $\left(\chi^{2}\right.$ $=14,48 ; \mathrm{P}<0,05)$ para a crioscopia. $\mathrm{Na}$ avaliação das rotas,constataram-se diferenças significativas para ambas as variáveis. Juramento apresentou maior frequência de amostras fora dos padrões de densidade, 4,4\% (Tab.1), enquanto Icaraí de Minas, maior ocorrência para a crioscopia, 7,84\% (Tab.1).

Identificou-se diferença significativa $(\mathrm{P}<0,05)$ para médias de acidez titulável, densidade e crioscopia entre os meses (Tab. 2). Embora dentro dos padrões normativos, maio e abril mostraram valores médios superiores para densidade, 1,03134 e $1,03125 \mathrm{~g} / \mathrm{mL}$, respectivamente. Para crioscopia, maio $\left(-0,5185^{\circ} \mathrm{C}\right)$ e junho $\left(-0,519^{\circ} \mathrm{C}\right)$ corresponderam às maiores médias, enquanto novembro $\left(-0,525^{\circ} \mathrm{C}\right)$ e setembro $\left(-0,524^{\circ} \mathrm{C}\right)$, às menores.

A acidez titulável, densidade e crioscopia diferiram significativamente quando comparadas entre as estações do ano. No período chuvoso, foram observadas maiores médias para acidez titulável $\left(15,7^{\circ} \mathrm{D}\right)$ e densidade $(1,031 \mathrm{~g} / \mathrm{mL})$, enquanto crioscopia foi superior no período seco, com $-0,521^{\circ} \mathrm{C}$ (Tab. 2).

Tabela 2. Resultados médios mensais das análises de acidez titulável, densidade e crioscopia do leite coletado por um laticínio do Norte de Minas Gerais, ao longo do ano de 2014

\begin{tabular}{lccccc}
\multicolumn{1}{c}{ Mês } & $\begin{array}{c}\text { Acidez titulável }\left({ }^{\circ} \mathrm{D}\right) \\
\mathrm{n}=9357\end{array}$ & $\begin{array}{c}\text { Densidade }(\mathrm{g} / \mathrm{mL}) \\
\mathrm{n}=9165\end{array}$ & $\begin{array}{c}\text { Crioscopia }\left({ }^{\circ} \mathrm{C}\right) \\
\mathrm{n}=9752\end{array}$ \\
\hline Janeiro & 15,98 & $\mathrm{a}$ & 1,03116 & $\mathrm{bc}$ & $-0,5226 \mathrm{c}$ \\
Fevereiro & 15,31 & $\mathrm{~cd}$ & 1,03119 & $\mathrm{~b}$ & $-0,5212 \mathrm{~b}$ \\
Março & 15,50 & $\mathrm{bc}$ & 1,03114 & $\mathrm{bc}$ & $-0,5236 \mathrm{~d}$ \\
Abril & 15,47 & $\mathrm{bc}$ & 1,03125 & $\mathrm{ab}$ & $-0,5209 \mathrm{~b}$ \\
Maio & 15,29 & $\mathrm{~cd}$ & 1,03134 & $\mathrm{a}$ & $-0,5185 \mathrm{a}$ \\
Junho & 14,99 & ef & 1,03103 & $\mathrm{c}$ & $-0,5190 \mathrm{a}$ \\
Julho & 14,78 & $\mathrm{f}$ & 1,03071 & $\mathrm{~d}$ & $-0,5224 \mathrm{c}$ \\
Agosto & 15,07 & $\mathrm{de}$ & 1,03062 & $\mathrm{de}$ & $-0,5210 \mathrm{~b}$ \\
Setembro & 15,67 & $\mathrm{~b}$ & 1,03053 & $\mathrm{e}$ & $-0,5240 \mathrm{de}$ \\
Outubro & 14,95 & ef & 1,03023 & $\mathrm{f}$ & $-0,5210 \mathrm{~b}$ \\
Novembro & 15,68 & $\mathrm{~b}$ & 1,03060 & $\mathrm{de}$ & $-0,5248 \mathrm{e}$ \\
Dezembro & 15,54 & $\mathrm{bc}$ & 1,03063 & $\mathrm{de}$ & $-0,5234 \mathrm{~d}$ \\
\hline
\end{tabular}

*Médias seguidas de letras diferentes na mesma coluna diferem pelo teste $\mathrm{T}(\mathrm{P}<0,05)$.

Quanto às rotas, foi constatada diferença significativa para as médias de acidez titulável, densidade e crioscopia (Tab.3). As rotas Bocaiúva $\left(14,71^{\circ} \mathrm{D}\right)$ e Juramento $\left(14,89^{\circ} \mathrm{D}\right)$ apresentaram menor acidez titulável, enquanto Ubaí $\left(15,85^{\circ} \mathrm{D}\right)$ e Icaraí de Minas $\left(15,67^{\circ} \mathrm{D}\right)$, as maiores. A rota de maior valor médio observado para densidade foi Pedras de Maria de Cruz $(1,03128 \mathrm{~g} / \mathrm{mL})$ e a menor, Bocaiúva $(1,03064 \mathrm{~g} / \mathrm{mL})$, a qual se diferenciou da maioria das outras, exceto de Juramento, com 1,03077g/mL. A menor média de crioscopia ocorreu na rota Icaraí de Minas (0,5226), sendo semelhante às de Bocaiúva ($\left.0,5215^{\circ} \mathrm{C}\right)$, Capitão Enéas $\left(-0,5224^{\circ} \mathrm{C}\right)$ e Ubaí ($\left.0,5223^{\circ} \mathrm{C}\right)(\mathrm{Tab} .3)$. 
Tabela 3. Resultados médios de acidez titulável, densidade e crioscopia quanto às diferentes rotas de coleta de amostras de leite fornecidas a um laticínio no Norte de Minas Gerais

\begin{tabular}{lcccccc}
\multicolumn{1}{c}{ Rotas } & $\begin{array}{c}\text { Acidez titulável }\left({ }^{\circ} \mathrm{D}\right) \\
\mathrm{n}=9357\end{array}$ & \multicolumn{2}{c}{$\begin{array}{c}\text { Densidade }(\mathrm{g} / \mathrm{mL}) \\
\mathrm{n}=9165\end{array}$} & \multicolumn{2}{c}{$\begin{array}{c}\text { Crioscopia }\left({ }^{\circ} \mathrm{D}\right) \\
\mathrm{n}=9752\end{array}$} \\
\hline Bocaíuva & 14,71 & $\mathrm{~d}$ & 1,03064 & $\mathrm{e}$ & $-0,5215$ & $\mathrm{ab}$ \\
Brasília de Minas & 15,30 & $\mathrm{bc}$ & 1,03086 & $\mathrm{~cd}$ & $-0,5211$ & $\mathrm{a}$ \\
Capitão Enéas & 15,32 & $\mathrm{bc}$ & 1,03081 & $\mathrm{~d}$ & $-0,5224$ & $\mathrm{~b}$ \\
Francisco Sá & 15,17 & $\mathrm{c}$ & 1,03086 & $\mathrm{~d}$ & $-0,5215$ & $\mathrm{a}$ \\
Icaraí de Minas & 15,67 & $\mathrm{a}$ & 1,03100 & $\mathrm{bc}$ & $-0,5226$ & $\mathrm{~b}$ \\
Juramento & 14,89 & $\mathrm{~d}$ & 1,03077 & $\mathrm{de}$ & $-0,5210$ & $\mathrm{a}$ \\
Montes Claros & 15,36 & $\mathrm{~b}$ & 1,03088 & $\mathrm{~cd}$ & $-0,5214$ & $\mathrm{a}$ \\
Pedras de Maria da & 15,31 & $\mathrm{bc}$ & 1,03128 & $\mathrm{a}$ & $-0,5210$ & $\mathrm{a}$ \\
Cruz & 15,85 & $\mathrm{a}$ & 1,03104 & $\mathrm{~b}$ & $-0,5223$ & $\mathrm{~b}$ \\
Ubaí & & &
\end{tabular}

* Médias seguidas de letras diferentes na mesma coluna diferem pelo teste $\mathrm{T}(\mathrm{P}<0,05)$.

Nota - Rotas: Bocaiúva (Bocaiúva); Brasília de Minas (municípios de Brasília de Minas, Coração de Jesus e São João da Lagoa); Capitão Enéas (Capitão Enéas e Janaúba); Francisco Sá (Francisco Sá); Icaraí de Minas (Icaraí de Minas e São Francisco); Juramento (Juramento e Glaucilândia); Montes Claros (Montes Claros); Pedras de Maria da Cruz (Pedras de Maria da Cruz, Japonvar, Lontra e São João da Ponte); e Ubaí.

No estudo de correspondências simples entre classes de leite e meses (Fig.1) e classes de leite e rotas (Fig.2), as duas dimensões formadas nos gráficos explicaram 91,01 e $91,62 \%$ da inércia acumulada, respectivamente. Setembro apresentou maior associação com LINA e leite ácido, enquanto abril,com leite normal. Considerando-se as rotas, pode ser observada relação entre LINA e a rota Icaraí de Minas e de leite normal às rotas de Capitão Enéas e Francisco Sá.

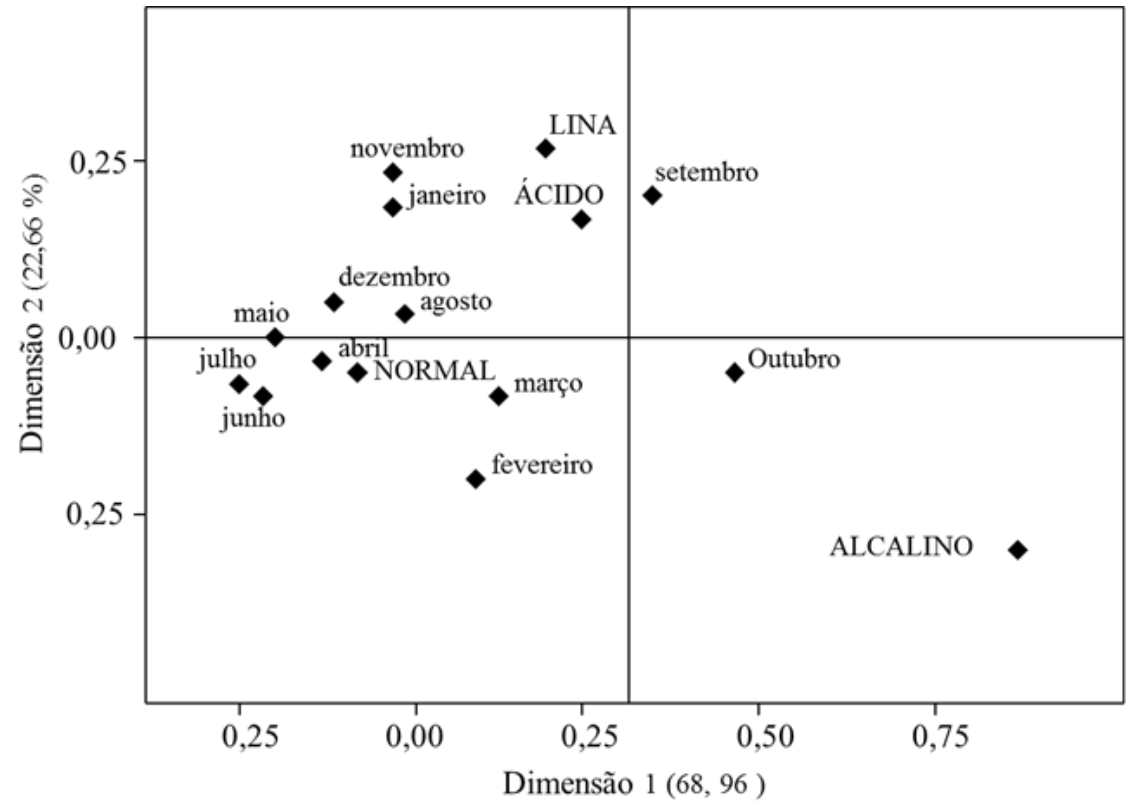

Figura 1. Gráfico de correspondência múltipla para classes de leite normal, ácido, alcalino e leite instável não ácido (LINA), coletado por um laticínio do norte de Minas Gerais,classificados conforme Instrução Normativa IN 76/2018 do Mapa (Brasil, 2018a), ao longo do ano de 2014, nas cidades de Bocaiúva, Brasília de Minas, Coração de Jesus São João da Lagoa, Capitão Enéas, Janaúba, Francisco Sá, Icaraí de Minas, São Francisco, Juramento, Glaucilândia, Montes Claros, Pedras de Maria da Cruz, Japonvar, Lontra, São João da Ponte e Ubaí. 


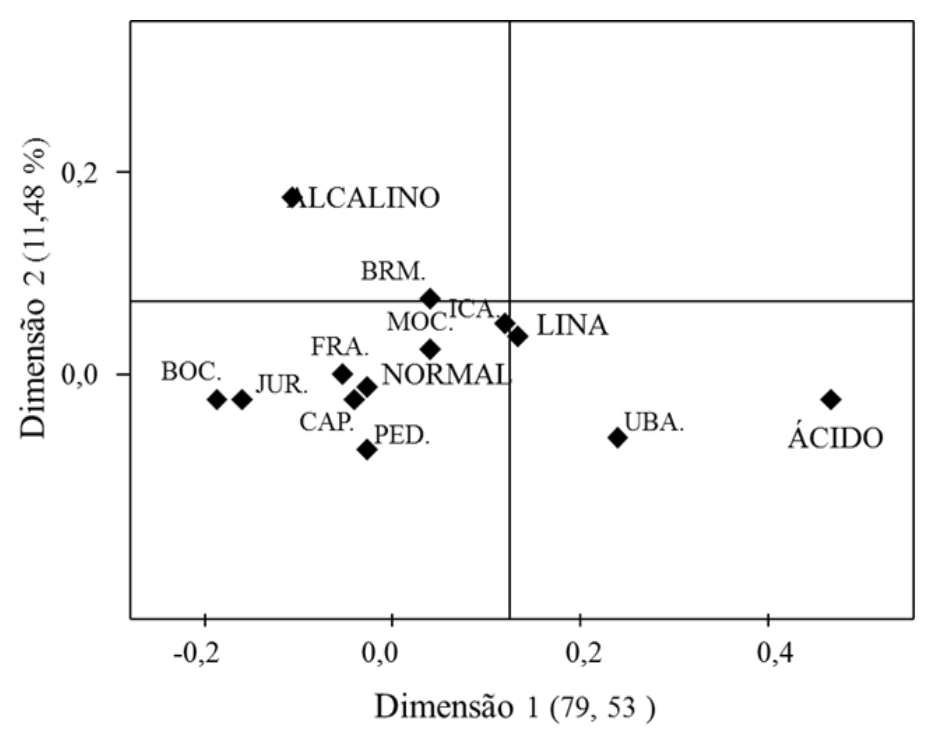

Figura 2. Gráfico de correspondência múltipla para as classes de leite normal, ácido, alcalino e leite instável não ácido (LINA), coletados por um laticínio do norte de Minas Gerais, classificados conforme Instrução Normativa IN 76/2018 do Mapa (Brasil, 2018a), entre rotas de coleta.

Nota -Rotas:Bocaiúva (BOC), Brasília de Minas (BRM), Capitão Enéas (CAP), Francisco Sá (FRA), Icaraí de Minas (ICA), Juramento (JUR), Montes Claros (MOC), Pedras de Maria da Cruz (PED), Ubaí (UBA).

As análises de correspondência múltipla para estação do ano, testes do álcool, acidez titulável, densidade e crioscopia determinaram associação entre a estação seca e a frequência de amostras dentro dos padrões, sendo explicadas por $52,23 \%$ da inércia acumulada no gráfico (Fig.3). Grupos de meses e de rotas foram significativos $(\mathrm{P}<0,05)$ para probabilidade de ocorrência de LINA, conforme a análise de regressão logística (Fig. 4). Por meio das razões de chances de ocorrência (odds ratio) estimadas (Fig.4), verificou-se que os grupos de meses 1, setembro e janeiro, e 4, agosto, novembro e dezembro, foram determinantes de maior chance de LINA. O grupo 3, composto por maio, junho e julho, demonstrou menor chance de ocorrência de LINA. A probabilidade para ocorrer LINA neste grupo correspondeu a $56 \%$ da chance de ocorrência em relação ao grupo 4, servindo como base de comparação na análise. Amostras do grupo 2, fevereiro, março, abril e outubro, evidenciaram $70 \%$ da probabilidade do grupo 4 para se apresentarem como LINA.

Em relação aos grupos de rotas formados por análises de correspondência múltipla, tomando
Bocaiúva como base comparativa dos resultados, as rotas Juramento e Bocaiúva apresentaram a mesma chance de ocorrência de LINA. Amostras provenientes da rota Ubaí possuíram maior chance de ser LINA. A possibilidade de uma amostra originada desse grupo ser LINA é 2,169 vezes superior às provenientes da rota Bocaiúva. A chance de amostras serem LINA é de 1,98 e 1,738 superior às provenientes da rota de Bocaiúva, respectivamente, nos grupos de rotas 4 (Icaraí de Minas e Brasília de Minas) e 5 (Pedras de Maria da Cruz, Montes Claros, Francisco Sá e Capitão Enéas).

A análise de variância entre meses formados por teste de agrupamento demonstrou diferença $(\mathrm{P}<0,05)$ para acidez titulável, densidade e crioscopia (Tab. 4). Setembro e janeiro apresentaram maior média de acidez titulável, $15,84^{\circ} \mathrm{D}$; agosto, novembro e dezembro, menor média de densidade, $1,03062 \mathrm{~g} / \mathrm{mL}$; e setembro e janeiro, agosto, novembro e dezembro,menor média de índice crioscópico, $-0,5230^{\circ} \mathrm{C}$ (Tab.4). 

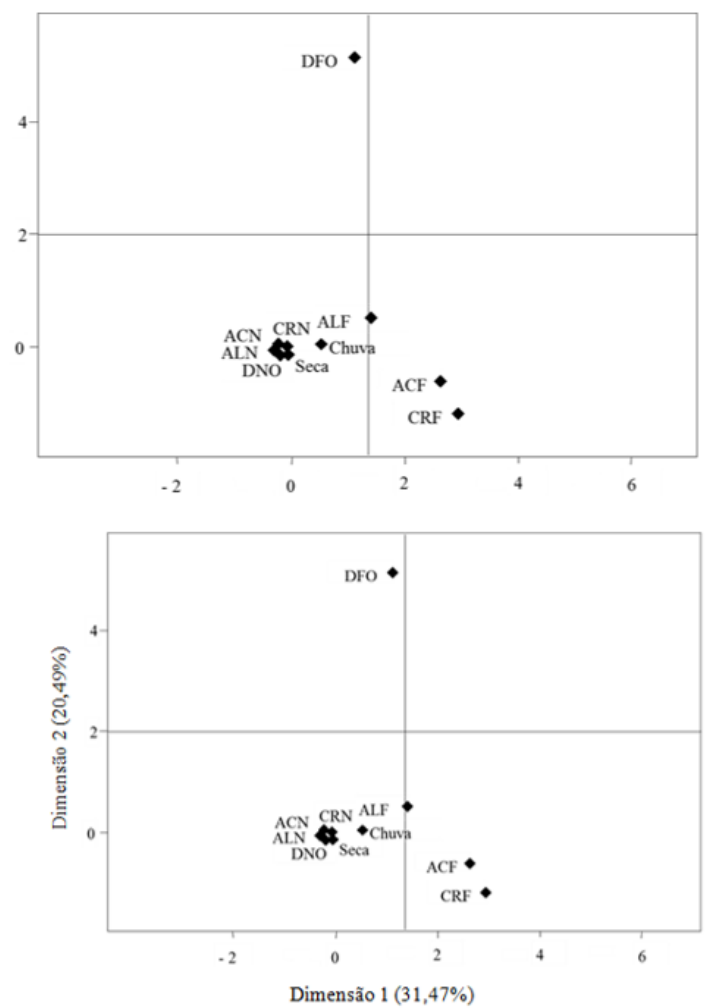

Figura 3. Análise de correspondência múltipla quanto ao resultado do teste do álcool, da acidez titulável, da densidade e da crioscopia do leite em relação à estação do ano, em dados de um laticínio do norte de Minas Gerais, classificados conforme Instrução Normativa IN 76/2018 do Mapa (Brasil, 2018a), ao longo do ano de 2014.

Nota - Amostras estáveis à prova do álcool: álcool padrão (ALP), amostras instáveis à prova do álcool:álcool fora do padrão (ALF), acidez normal (ACN), acidez fora do padrão (ACF), densidade normal (DNO), densidade fora do padrão (DFO), crioscopia normal (CRN), crioscopia fora do padrão (CRF). Chuva: estação chuvosa, de novembro a março; seca: estação seca, de abril a outubro.

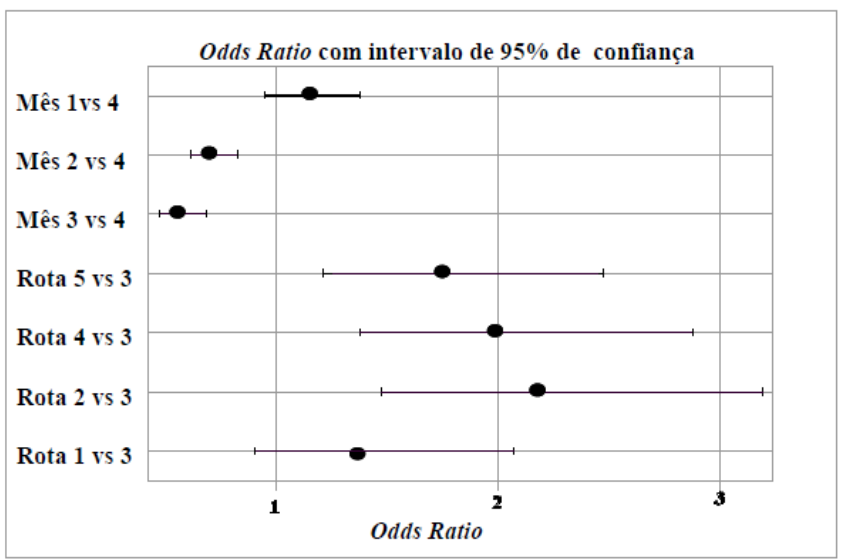

Figura 4. Valores de odds ratio para comparação de grupos de meses e de rotas na avaliação de LINA em dados de um laticínio do norte de Minas Gerais, classificados conforme Instrução Normativa IN 76/2018 do Mapa (Brasil, 2018a), ao longo do ano de 2014.

Nota - Grupo de meses: 1. setembro e janeiro, 2. fevereiro, março, abril e outubro, 3. maio, junho e julho, 4. agosto, novembro e dezembro. Grupo de rotas: 1. Juramento, 2. Ubaí, 3. Bocaiúva, 4. Icaraí de Minas e Brasília de Minas, 5. Pedras de Maria da Cruz, Montes Claros, Francisco Sá e Capitão Enéas. 
Tabela 4. Comparação de médias entre agrupamentos de meses para acidez titulável, densidade e crioscopia de amostras de leite fornecidas a um laticínio no Norte de Minas Gerais

\begin{tabular}{llll}
\hline Grupos de meses & $\begin{array}{l}\text { Acidez titulável }\left({ }^{\circ} \mathrm{D}\right) \\
\mathrm{n}=9357\end{array}$ & $\begin{array}{l}\text { Densidade }(\mathrm{g} / \mathrm{mL}) \\
\mathrm{n}=9165\end{array}$ & $\begin{array}{l}\text { Crioscopia }\left({ }^{\circ} \mathrm{C}\right) \\
\mathrm{n}=9752\end{array}$ \\
\hline 1 - setembro e janeiro & $15,84 \mathrm{a}$ & $1,03097 \mathrm{ab}$ & $-0,5230 \mathrm{c}$ \\
2 - fevereiro, março, abril e outubro & $15,30 \mathrm{~b}$ & $1,03091 \mathrm{~b}$ & $-0,5214 \mathrm{~b}$ \\
3 - maio, junho e julho & $15,00 \mathrm{c}$ & $1,03101 \mathrm{a}$ & $-0,5201 \mathrm{a}$ \\
4 - agosto, novembro e dezembro & $15,39 \mathrm{~b}$ & $1,03062 \mathrm{c}$ & $-0,5230 \mathrm{c}$ \\
\hline
\end{tabular}

*Médias seguidas de letras diferentes na mesma coluna diferem pelo teste $\mathrm{T}(\mathrm{P}<0,05)$

Nota- Grupos de meses obtidos por análise correspondência múltipla.

Na comparação dos grupos formados pelas rotas (Tab.5), verificou-se diferença nas médias observadas de acidez titulável, densidade e crioscopia. As rotas de Juramento e Bocaiúva apresentaram menor acidez titulável e menor densidade quando comparadas aos outros grupos de rotas. Para a crioscopia, a rota de Juramento diferiu de todas as outras, apresentando maior índice crioscópico, $-0,5210^{\circ} \mathrm{C}$.

Tabela 5. Comparação de médias entre agrupamentos de rotas para acidez titulável, densidade e crioscopia de amostras de leite fornecidas a um laticínio no Norte de Minas Gerais

\begin{tabular}{llll} 
Grupos de rotas & $\begin{array}{l}\text { Acidez titulável }\left({ }^{\circ} \mathrm{D}\right) \\
\mathrm{n}=9357\end{array}$ & $\begin{array}{l}\text { Densidade } \\
(\mathrm{g} / \mathrm{mL}) \\
\mathrm{n}=9165\end{array}$ & $\begin{array}{l}\text { Crioscopia }\left({ }^{\circ} \mathrm{C}\right) \\
\mathrm{n}=9752\end{array}$ \\
\hline $\begin{array}{l}\text { 1- Juramento } \\
\text { 2-Ubaí }\end{array}$ & $\begin{array}{l}14,89 \mathrm{~d} \\
15,85 \mathrm{a}\end{array}$ & $1030,77 \mathrm{c}$ & $-0,52104 \mathrm{a}$ \\
3- Bocaiúva & $14,71 \mathrm{~d}$ & $1031,04 \mathrm{a}$ & $-0,52238 \mathrm{~b}$ \\
$\begin{array}{l}\text { 4 - Icaraí de Minas e Brasília de } \\
\text { Minas }\end{array}$ & $15,42 \mathrm{~b}$ & $1030,91 \mathrm{c}$ & $-0,52156 \mathrm{a}$ \\
5 - Pedras de Maria da Cruz, Montes & $15,27 \mathrm{c}$ & $1030,89 \mathrm{~b}$ & $-0,52159 \mathrm{a}$ \\
\end{tabular}

Claros, Francisco Sá e Capitão Enéas

* Médias seguidas de letras diferentes na mesma coluna diferem pelo teste $\mathrm{T}(\mathrm{P}<0,05)$.

Nota- Grupos de rotas obtidos por análise correspondência múltipla. Rotas: Bocaiúva (Bocaiúva); Brasília de Minas (municípios de Brasília de Minas, Coração de Jesus e São João da Lagoa); Capitão Enéas (Capitão Enéas e Janaúba); Francisco Sá (Francisco Sá); Icaraí de Minas (Icaraí de Minas e São Francisco); Juramento (Juramento e Glaucilândia); Montes Claros (Montes Claros); Pedras de Maria da Cruz (Pedras de Maria da Cruz, Japonvar, Lontra e São João da Ponte); e Ubaí. Análises de correspondência múltipla determinaram os agrupamentos de rotas.

\section{DISCUSSÃO}

Foi identificada maior porcentagem de amostras dentro da normalidade e baixa ocorrência de LINA (Tab.1), embora tenham sido constatadas alterações quanto à estabilidade do leite. A predominância de animais geneticamente menos especializados para a produção de leite pode justificar esse resultado. Eram recebidos pelo laticínio, em média, 30.000 litros de leite por dia e, considerando-se as 290 UPL, a produção média diária era aproximadamente de 103 litros de leite. Na maioria das UPL do Norte de Minas Gerais, encontram-se animais mestiços (azebuados, anelorados e sem raça definida), criados em sistema semiextensivo e com menores índices de produtividade (Menezes et al., 2014), os quais são menos exigentes do ponto de vista nutricional, se comparados às raças mais produtivas.

Bovinos leiteiros altamente especializados apresentam maior demanda de nutrientes e alta produção de calor metabólico, sendo mais sensíveis às variações no manejo e na alimentação (Rhoads et al., 2009). Ferraretto et al. (2014) substituíram $50 \%$ da dieta de vacas em lactação por palha de arroz e constataram redução da glicemia e insulina circulantes, além de $40 \%$ de diminuição na produção de leite.

Vacas leiteiras mantidas em condições nutricionais não ajustadas ao potencial genéticos e tornam mais propensas a perturbações metabólicas, tais como alterações dos hormônios ligados à gliconeogênese e ao metabolismo de 
gorduras, condições comprometedoras da qualidade e da composição do leite (Gabbi et al., 2016). A deficiência de nutrientes provoca aumento da permeabilidade de tight junctions nas células mamárias e reduz a estabilidade do leite por aumentar a concentração de $\beta$-caseína e de proteína total, em detrimento da concentração de -caseína, o que propicia menor estabilidade do leite ao etanol (Stumpf et al., 2013). Segundo Fagnani et al. (2018), a instabilidade ao álcool aumenta com a menor concentração de lactose e, indiretamente, com a diminuição de $\alpha$ lactalbumina, promotor da síntese de lactose.

Souza et al. (2011), ao avaliarem leite $(\mathrm{n}=276) \mathrm{em}$ Viçosa-AL, constataram $83 \%$ de amostras normais. Considerando-se somente as amostras positivas ao teste do álcool a $72 \%$, a frequência de LINA foi de 64,77; 66 e 65,9\%, conforme Lopes (2008), Azevedo (2014) e Faria et al. (2017), respectivamente, sendo próximas aos65,41\% verificados no presente estudo. Lopes (2008), no estado de São Paulo, e Azevedo (2014), no sul do Brasil, relataram, respectivamente, $25,5 \%$ e $19,8 \%$ de LINA e $14 \%$ e $10,2 \%$ de amostras ácidas, porcentagens mais elevadas se comparadas ao descrito na Tab. 1. Fagnani et al. (2018) descreveram 32\% de 180 amostras instáveis ao álcool. Assim, por se tratar de região com animais de menor potencial genético para a produção de leite, pode ser justificada a menor ocorrência de LINA e o baixo índice de amostras em desconformidade com a presente pesquisa (Tab.1). Comportamentos distintos podem ser explicados pelas características das explorações nas propriedades, dos rebanhos e das condições climáticas regionais, pois a alteração dos aspectos físicos do leite é de natureza multifatorial (Zanela et al., 2009; Fagnani et al., 2018).

Verificou-se maior representatividade na frequência de amostras positivas ao teste do álcool no final do inverno ou período seco (Tab.1). A ocorrência de LINA foi associada à transição da época seca para a chuvosa, sendo agosto a janeiro os meses de maior ocorrência (Tab.1). A análise de regressão logística também justifica isso (Fig. 4), e os grupos de meses 1 (setembro e janeiro) e 4 (agosto, novembro e dezembro) evidenciaram maior probabilidade de ocorrência de LINA. O aumento de amostras positivas à prova do álcool e de LINA ocorreu mais no final da estação seca, quando é verificada baixa disponibilidade de forragens e maior a restrição alimentar.
No início do período de rebrota das pastagens, há maiores chances de acontecer restrição alimentar (Fernandes et al., 2013), configurada como baixa ingestão de matéria seca e/ou tempo de alimentação insuficiente (Zanela e Ribeiro, 2018).A redução do aporte de energia ao tecido epitelial mamário interfere na estabilidade do leite (Gabbi et al., 2016). Em regiões tropicais semiáridas, a estação seca é considerada fator limitante à qualidade da matéria-prima (Faria $e t$ al., 2017). O clima quente e seco e de baixo índice pluviométrico tende a ser mais determinante nas variações de estabilidade térmica das amostras de leite (Fernandes et al., 2013).

Segundo Rhoads et al. (2009) e Sevi e Caroprese (2012), a exposição de rebanhos a altas temperaturas pode contribuir para reduzir o conteúdo proteico no leite, pois o aumento da permeabilidade dos capilares sanguíneos favorece a elevação da quantidade de enzimas proteolíticas. Esperam-se, desse modo, valores de $\mathrm{pH}$ mais elevados e de acidez titulável mais baixos em animais sob estresse térmico por calor (Botaro et al., 2009).

Maior número de amostras foi considerado apto ao processamento industrial quanto à acidez titulável, crioscopia e densidade (Tab.1), com valores de acordo com os padrões estabelecidos em Brasil (2018a). Fernandes et al. (2013), no norte de Minas Gerais, observaram situação similar para acidez titulável e densidade em diferentes épocas do ano. Os valores médios obedeceram à tendência semelhante à verificada no presente estudo, com variação de 14 a $15^{\circ} \mathrm{D}$ e de 1,030 a $1,031 \mathrm{~g} / \mathrm{mL}$, respectivamente. Ciprandi (2014) e Ponce e Hernández (2001), em Porto Alegre-RS, verificaram semelhança para crioscopia entre os meses do ano, enquanto Martins et al. (2006), na região da Bacia de Pelotas-RS, e Botaro et al. (2007), em Pirassununga-SP, relataram influência sazonal no aumento desse parâmetro, o qual foi associado à estação seca e aos meses mais quentes do ano.

A maior acidez titulável no período chuvoso pode estar relacionada às condições típicas dessa estação. Maiores índices de umidade e temperatura, além das condições de higiene inadequadas, colaboram para a proliferação de microrganismos mesófilos, acidificando o leite por meio da fermentação da lactose (Chavez et al., 2004). Conforme Marques et al. (2007), a 
acidificação acarreta desestruturação das micelas de caseína e formação de coágulo, sendo um dos problemas detectados com maior frequência na plataforma de recebimento de laticínios. A pequena variação da densidade do leite e a semelhança entre as estações indicam não existir adulteração evidente.

A diminuição do índice crioscópico no período chuvoso pode estar relacionada ao aumento da acidez titulável (Fonseca et al., 1995), e foi verificada correlação de $-0,5598$ entre essas variáveis, ou seja, para as mesmas amostras, quando observados altos valores de acidez titulável, verificou-se a tendência para baixos índices crioscópicos. Em contrapartida, na estação seca, o possível aumento da crioscopia do leite pode ser relacionado ao efeito de concentração dos constituintes sólidos, geralmente em consequência da menor da produção nesse período do ano (Paiva et al., 2012).

As rotas de Ubaí, Brasília de Minas e Icaraí de Minas estiveram mais associadas à presença de LINA e apresentaram maior número de amostras em desconformidade (Tab.1). Variações nas características das amostras estudadas podem estar associadas à distância do laticínio, pois Ubaí, Brasília de Minas e Icaraí de Minas se encontram mais distantes da indústria em relação às outras rotas de coleta, afastados a $167,7 \mathrm{~km} ; 106 \mathrm{~km}$ e $152,9 \mathrm{~km}$, respectivamente. Essas distâncias resultaram em maior tempo de transporte até o laticínio. Nesta pesquisa, todos os tanques eram situados em locais apropriados; o tempo máximo de estocagem do leite nesses era de $48 \mathrm{~h}$, em temperaturas inferiores ou iguais a $3,9^{\circ} \mathrm{C}$; a temperatura de transporte no caminhão isotérmico não ultrapassava $10^{\circ} \mathrm{C}$, verificada para o recebimento do leite no laticínio, em conformidade com Brasil (2011), vigente no ano de recebimento da matéria-prima; e os produtores foram treinados por técnicos do laticínio para seguirem as boas práticas antes e durante a obtenção e o armazenamento do leite. Portanto, o efeito mais pronunciado neste trabalho encontrase na maior distância da rota de coleta.

Desse modo, pode ter ocorrido efeito da rota por causa da possível multiplicação microbiana das amostras, que demoravam até $12 \mathrm{~h}$ para chegarem ao laticínio, se comparadas às mais próximas, recebidas em até três horas. Assim, é importante maior acompanhamento da indústria nas localidades que demonstraram problemas, visando a reduzir o número de amostras em desconformidade e os prejuízos aos produtores e ao laticínio.

\section{CONCLUSÃO}

A maioria das amostras de leite recebidas por um laticínio localizado no Norte de Minas Gerais atendeu aos padrões de estabilidade ao álcool, acidez titulável, densidade e crioscopia. Amostras positivas ao teste do álcool foram mais frequentes no final do inverno, correspondendo ao período seco do ano. Leite instável não ácido associou-se à transição da época seca do ano para a chuvosa, o que demonstra chances superiores de ocorrência em setembro e janeiro. As rotas de Brasília de Minas, Icaraí de Minas e Ubaí apresentaram mais amostras em desconformidade, sendo as de maior probabilidade para a ocorrência de leite instável não ácido. Avaliações complementares devem ser realizadas nessas rotas para serem estabelecidos e controlados os fatores predisponentes dessa alteração.

\section{REFERÊNCIAS}

ÁLVARES, C.A., STAPE, J.L., SENTELHAS, P.C. et al. Köppen's climate classification map for Brazil. Meteorol. Z., v.22, p.711-728, 2013.

AZEVEDO, C. S. Ocorrência de leite instável não ácido (LINA) na Região da Grande Florianópolis - SC. 2014. 28f. Monografia (Graduação em Zootecnia) - Faculdade de Zootecnia, Universidade Federal de Santa Catarina, Florianópolis, SC.

BASE SAS®9.4 procedures guide. Cary-NC: SAS Institute Inc. Help/ The VARCOMP Procedure/Details/ Computational Methods, 2011.

BOTARO, B.G.; LIMA, Y.V.L.; CORTINHAS, C.S. et al. Effect of the kappa-casein gene polymorphism, breed and seasonality on physicochemical characteristics, composition and stability of bovine milk. Rev. Bras. Zootec.; v.38, p.2447-2454, 2009.

BOTARO, B.G.; LIMA, Y.V.L.; AQUINO, A.A. et al. Polimorfismo da beta-lactoglobulina não afeta as características físico-químicas e a estabilidade do leite bovino. Pesqui. Agropecu. Bras., v.42, p.747-753, 2007. 
BOVINOCULTURA de leite e corte. Belo Horizonte: SEAPA / Subsecretaria de Política e Economia Agrícola de Minas Gerais, 2019, p.5$27 . \quad$ Disponível em: <http://www.reformaagraria.mg.gov.br/images/d ocumentos/bovinocultura_leite_corte_jul_2019[1 ].pdf>. Acessado em: 17 jul. 2019.

BRASIL. Ministério de Agricultura, Pecuária e Abastecimento (MAPA). Instrução Normativa $\mathrm{N}^{\circ}$ 62, de 29 de dezembro de 2011, Aprovar o Regulamento Técnico de Produção, Identidade e Qualidade do Leite tipo A. Diário Oficial da República Federativa do Brasil, Brasília, DF, 30 dez. 2011. Disponível em: <http://www.jusbrasil.com.br/diarios/33395065/ dou-secao-1-30-12-2011-pg-6>. Acessado em: 13 ago. 2017.

BRASIL. Ministério de Agricultura, Pecuária e Abastecimento (MAPA). Instrução Normativa $\mathrm{N}^{\circ}$ 76 , de 26 de dezembro de 2018a. Ficam aprovados os Regulamentos Técnicos que fixam a identidade e as características de qualidade que devem apresentar o leite cru refrigerado, o leite pasteurizado e o leite pasteurizado tipo A. Diário Oficial da República Federativa do Brasil, Brasília, DF, 30 nov. 2018. Disponível em:<http://pesquisa.in.gov.br/imprensa/jsp/visual iza/index.jsp?data=30/11/2018\&jornal=515\&pag ina $=9>$. Acesso em: 12 nov. 2019.

BRASIL. Ministério de Agricultura, Pecuária e Abastecimento (MAPA). Instrução Normativa $\mathrm{N}^{\circ}$ 77, de 26 de dezembro de 2018b. Ficam estabelecidos os critérios e procedimentos para a produção, acondicionamento, conservação, transporte, seleção e recepção do leite cru em estabelecimentos registrados no serviço de inspeção oficial. Diário Oficial da República Federativa do Brasil, Brasília, DF, 30 nov. 2018. Disponível em: <http://pesquisa.in.gov.br/imprensa/jsp/visualiza/ index.jsp?data $=30 / 11 / 2018 \&$ jornal $=515 \&$ pagina =10>. Acesso em: 12 nov. 2019.

CIPRANDI, A. Caracterização fisico-química do leite normal e do leite instável não ácido (LINA). 2014. 64f. Dissertação (Mestrado em Ciências Veterinárias) - Faculdade de Veterinária, Universidade Federal do Rio Grande do Sul, Porto Alegre, RS.
CHAVEZ, M.; NEGRI, L.; TAVERNA, M.A.; CUATRÍN, A. Bovine milk composition parameters affecting the ethanol stability. J. Dairy Res., v.71, p.201-206, 2004.

FAGNANI, R.; ARAÚJO, J.P.A.; BOTARO, B.G. Field findings about milk etanol stability: a first report of interrelationship between $\alpha$ lactalbumin and lactose. J Sci. Food Agric., v.98, p.2787-2792, 2018.

FARIA, P.F.; RANGEL, A.H.N.; URBANO, S.A. et al. Unstable milk occurrence in the semi-arid region and its relation with the physico-chemical characteristics of milk. Livest. Res. Rural Devel.,v.29, p.1-8, 2017.

FERNANDES, R.F.; PEREIRA, A.S.F.; PINHO, L. Influência da sazonalidade em parâmetros físico-químicos do leite cru recebido por um laticínio no Norte de Minas Gerais. Rev. Inst. Lat. Cândido Tostes, v.68, p.36-41, 2013.

FERRARETTO, L.F.; GENCOGLU, H.; HACKBART, K.S. et al. Effect of feed restriction on reproductive and metabolic hormones in dairy cows. J. Dairy Sci., v.97, p.754-763, 2014.

FONSECA, L.M.; RODRIGUES, R.; SOUZA, M.R. Índice crioscópico do leite. Cad. Tec. Esc. Vet. UFMG, n.13, p.73-83, 1995.

GABBI, A.M.; MCMANUS, C.M.; ZANELA, M.B. et al. Milk traits of lactating cows submitted to feed restriction. Trop. Anim. Health Prod., v.48, p.37-43, 2016.

LI, S.; YE, A.; SINGH, H. Seasonal variations in composition, properties, and heat-524 induced changes in bovine milk in a seasonal calving system. J. Dairy Sci., v.102, p.7747-7759, 2019.

LOPES, L. C. Composição e características físico-químicas do leite instável não ácido (LINA) na região de Casa Branca, Estado de São Paulo. 2008. 63f. Dissertação (Mestrado em Zootecnia) - Faculdade de Zootecnia e Engenharia de Alimentos, Universidade de São Paulo, Pirassununga, SP.

MARTINS, P.R.G.; SILVA, C.A.; FISCHER, V. et al. Produção e qualidade do leite na bacia leiteira de Pelotas-RS em diferentes meses do ano. Ciênc. Rural, v.36, p.209-214, 2006. 
MARQUES, L.T.; ZANELA, M.B.; RIBEIRO, M.E.R. et al. Ocorrência do leite instável ao álcool $76 \%$ e não ácido (LINA) e efeito sobre os aspectos físico-químicos do leite. Rev. Bras. Agrosci., v.13, p.91-97, 2007.

MENEZES, I.R.; ALMEIDA, A.C.; PINTO, M.S. et al. Caracterização de unidades agrícolas familiares produtoras de leite no Norte do estado de Minas Gerais. Rev. Inst. Lat. Cândido Tostes, v.69, p.153-163, 2014.

PAIVA, C.A.V.; CERQUEIRA, M.M.O.P.; SOUZA, M.R.S.; LANA, A.M.Q. Evolução anual da qualidade do leite cru refrigerado processado em uma indústria de Minas Gerais. Arq. Bras. Med. Vet. Zootec., v.64, p.471-478, 2012.

PONCE, P.C.; HERNÁNDEZ, R. Propriedades físico-químicas do leite e sua associação com transtornos metabólicos e alterações na glândula mamária. In: GONZÁLEZ, F.H.D.; DURR, J.W.; FONTANELI, R.S. (Eds.). Uso do leite para monitorar a nutrição e o metabolismo de vacas leiteiras. Porto Alegre: Universidade Federal do Rio Grande do Sul, 2001. p.61-72.

RHOADS, M.L.; RHOADS, R.P.; VANBAALE, M.J. et al. Effects of heat stress and plane of nutrition on lactating Holstein cows: I. Production, metabolism, and aspects of circulating somatotropin. J. Dairy Sci., v.92, p.1986-1987, 2009.
SEVI, A.; CAROPRESE, M. Impact of heat stress on milk production, immunity and udder health in sheep: A critical review. Small Ruminant Res., v.107, p.1-7, 2012.

STUMPF, M.T.; FISCHER, V.; MCMANUS, C.M. et al. Severe feed restriction increases permeability of mammary gland cell tight junctions and reduces ethanol stability of milk. Animal, v.7, p.1137-1142, 2013.

SOUZA, P.P.M.; SOARES, K.D.A.; LIMA FILHO, C.F. et al. Ocorrência do leite instável não ácido em vacas leiteiras no município de Viçosa-AL. Vet. Notícias, v.17, p.144-147, 2011.

ZANELA, M.B.; RIBEIRO, M.E.R.; FISCHER, V. et al. Ocorrência do leite instável não ácido no noroeste do Rio Grande do Sul. Arq. Bras. Med. Vet. Zootec., v.61, p.1009-1013, 2009.

ZANELA, M.B.; RIBEIRO, M.E.R. LINA -leite instável não ácido. Pelotas: EMBRAPA, 2018. $17 \mathrm{p}$. 